Session No. 2532

\title{
Topical Learning as an Outcomes Assessment Tool
}

\author{
Tom Thomas, Martin Parker \\ University of South Alabama, Mobile, Alabama
}

\begin{abstract}
The University of South Alabama (USA) Electrical and Computer Engineering Department teaches an introductory electrical circuits class at the sophomore level, in which it is important that certain critical topics be mastered for future use in the curriculum. Historically, the class was infamous for drop/failure rates in excess of 50\%. A restructured class format was found to be effective, reducing the failure rate to less than $10 \%$ over four semesters. A population of 30 students volunteered to participate in a study in spring semester 2003. Students filled out questionnaires on three representative topics in USA's EG 220 electric circuits class. After a topic was covered, a homework sequence was assigned and a problem session was conducted in which the students were encouraged to ask questions. A questionnaire was given to each student in which they rated their level of understanding. A quiz was then given. The data indicates a high correlation between perceived understanding and quiz grades after the student has had the opportunity to reinforce each topic by working homework problems and asking questions. The instructor can quickly modify the presentation of course material to emphasize areas in which students are having difficulty. Students having particular difficulty are identified early and matched with a supplementary instructor. It was determined that course material offered in this manner significantly increased the success rate of the students without compromising the level of education.
\end{abstract}

\section{Introduction}

The University of South Alabama College of Engineering has five ABET-accredited undergraduate programs. ${ }^{1}$ At the freshman and sophomore level, there are a number of service classes that are taught to students in more than one program. Electrical Circuits (EG 220) is a service class taken by students in Mechanical, Computer, and Electrical Engineering. The only prerequisite is one semester of calculus. The class is offered every semester with an average enrollment of 50 students. A faculty member from the Department of Electrical and Computer Engineering (ECE) typically teaches EG 220. The class is a prerequisite for all other ECE classes

The class has typically been taught in a three-hour lecture format with two or three classroom tests and a final exam. In the past, there has often been a bimodal distribution of grades, indicating that one group of students was doing well and another group of students was doing significantly more poorly. The drop and failure rates have been high, sometimes approaching $50 \%$. To try to explain this situation, discussions were held with students who had done well in EG 220 and students who had done poorly in EG 220. Although not a formal study, some 
interesting facts emerged. For example, many students who perform poorly are students that received transfer credit for calculus. This is somewhat surprising, since the majority of the mathematics used in EG 220 doesn't require calculus-related concepts. Apparently some students have problems making a transition between calculus and circuits, going from abstract mathematical drills to practical application of mathematical principles. They have a tendency to regurgitate information. They "pattern match" when solving problems rather than learning and using techniques.

Another discussion topic concerned learning styles. It was found that students that do poorly in EG 220 are aware of the fact that they are doing poorly, but they don't know what to do about it. When they don't understand something in class or have trouble with homework, they are reluctant to ask questions because they don't want to look stupid. In contrast, the people who do well in EG 220 are significantly more willing to speak up when they have trouble. The people who did well said that working homework problems and asking questions were the most beneficial learning tools. The people who did more poorly said that they found more worked-out examples and practical applications were the most beneficial learning tools.

There was also a group of students that did poorly for more obvious reasons, such as not doing homework and missing tests. Since homework was not formally assigned and collected in past offerings of EG 220, the relationship between poor grades and lack of completion of homework assignments could not be formally established. The same problem exists with students that routinely missed lectures, since attendance has not been required or monitored in the past.

One thing that consistently came out is that students seem to know how they are doing, good or bad. There is also a tendency for students that are doing poorly to keep it quiet. After some reflection and discussion among faculty members that teach EG 220, it was decided to change the format of the class to try to address some of these issues. ${ }^{2}$

\section{Discussion}

The format of EG 220 was changed in Spring Semester 2002. The class material was organized into self-contained topics. Topics are now presented in the context of "tools to be mastered" by assigning homework on each topic, then discussing the homework in detail. It is difficult for some students to learn to think in terms of a solution process on problems that have more than one path of solution. The solution of circuit problems is presented as a process rather than a single task. Students are encouraged to think in terms of the application of tools in a particular sequence. Circuits are "disassembled" with the tools.

For each topic:

- A lecture is given

- Homework is assigned

- Homework is collected and graded

- A problem session is conducted

- A quiz is given

Each class is opened with questions about homework problems. 
On the homework due date, a problem session is conducted. Homework problems, improvised problems, and textbook problems not assigned as homework are covered.

In the first semester that EG 220 was offered in the new format, failures went down and the drop rate went down. Modifications to the topics and the presentation were made over several semesters, but the general format remained the same. For example, it was determined that weekly quizzes on topics were preferred by the students over classroom tests. The more immediate feedback on learning a specific topic was more useful, in the student's opinion, than the delayed feedback of a classroom test.

\begin{tabular}{|c|c|c|c|c|c|c|c|c|c|c|c|}
\hline EG 220 & g 2002 & $\%$ & EG 220 & $\overline{002}$ & $\%$ & EG 220 & g 2003 & $\%$ & EG 220 & & $\%$ \\
\hline$A$ & 39 & 70.91 & $A$ & 28 & 49.12 & $A$ & 15 & 50.00 & $A$ & 26 & 45.61 \\
\hline B & 11 & 20.00 & B & 9 & 15.79 & B & 3 & 10.00 & B & 8 & 14.04 \\
\hline C & 5 & 9.09 & C & 6 & 10.53 & C & 5 & 16.67 & C & 7 & 12.28 \\
\hline D & 0 & 0.00 & D & 4 & 7.02 & D & 0 & 0.00 & D & 4 & 7.02 \\
\hline $\mathrm{F}$ & 0 & 0.00 & $\mathrm{~F}$ & 5 & 8.77 & $\mathrm{~F}$ & 2 & 6.67 & $\mathrm{~F}$ & 2 & 3.51 \\
\hline Drop & 3 & 5.45 & Drop & 5 & 8.77 & Drop & 5 & 16.67 & Drop & 10 & 17.54 \\
\hline Total & 55 & & Total & 57 & & Total & 30 & & Total & 57 & \\
\hline
\end{tabular}

Table 1 - Grades and enrollment for EG 220 in 2002 and 2003.

In spring semester of 2003, it was decided that a study on the topical learning technique would be conducted. The new format of the course appeared to be working well. Two groups of students had progressed to the next series of courses and most of the students seemed to be well prepared, with a good mastery of the EG 220 subject material. There were, however, still failures in the class that could not be explained by missed classes and incomplete homework assignments. Also, the drop rate as a percentage of class enrollment was still high. If these students could be identified and targeted early, perhaps their overall class grades could be improved, or perhaps they would not find it necessary to drop the class.

One way to identify students with fundamental problems with course material is to simply ask them. ${ }^{3}$ The question then becomes "How well does a student's perceived understanding of a subject correlate with his actual understanding?" Would it be beneficial, for example, to ask students to complete a short topical questionnaire after turning in a homework assignment and before taking a quiz on the subject matter? If students say they understand a topic, then they are ready for a quiz. If a significant number say they don't, then more example problems are needed, or perhaps some clarification in lecture is needed.

The EG 220 spring 2003 class volunteered to fill out questionnaires on three topics out of the 12 topics covered in the semester. For each of the three topics, a lecture was given, a homework assignment was given, a problem session was conducted and a questionnaire was completed prior to a quiz. On the questionnaire, the students rated their level of understanding on a 1 to 10 scale, where 10 represented a good understanding. The students then took a quiz on the topic. The enrollment for Spring 2003 was 30 students. The following relationships were investigated:

- Student's understanding vs. Quiz average 
- Student's understanding vs. Final exam grade

- Student's understanding vs. Final grade

\section{Results:}

Figure 1 shows the relationship between student's understanding as reported on the questionnaire for a specific topic and the quiz grade for that topic. For a student that has a good grasp of the material and knows it, his level of understanding and quiz grade will produce a point in the shaded region of the plot. The shaded region corresponds to an area where the student's understanding and grades are resulting in a passing grade. In Figure 1, the class as a whole shows a good understanding of the particular topic. Twenty students out of twenty-three respondents showed an acceptable familiarity with the topic as validated by their quiz grade.

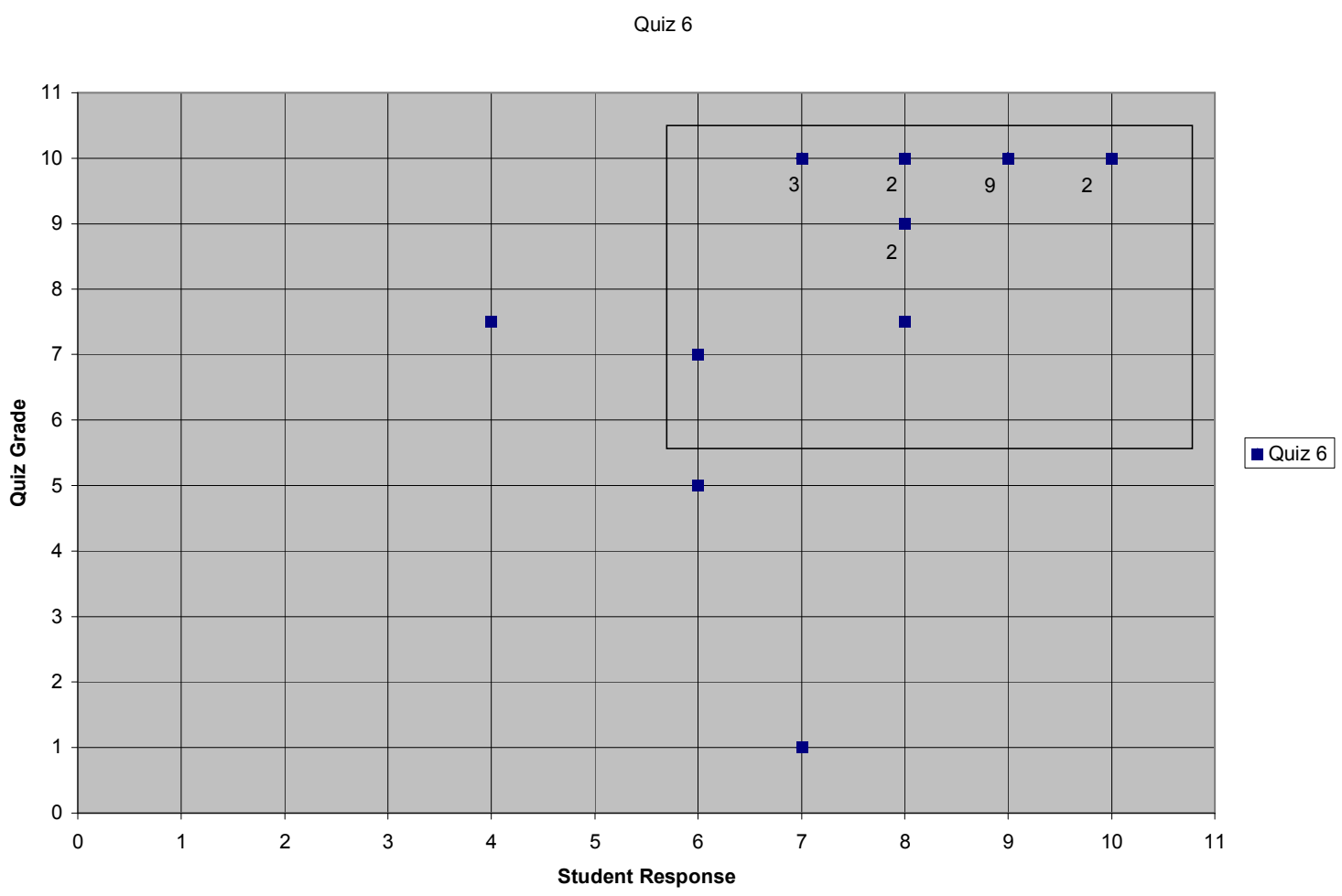

Figure 1 - Student understanding vs. quiz grade for a topic quiz.

Figure 2 shows the relationship between student understanding (averaged over three topics) and the overall course quiz average. A total of ten quizzes were given in the course. The quiz average for this particular semester accounted for $50 \%$ of the class grade. As can be seen in Figure 2, there is a correlation between the average of the student's understanding on three topics and the overall quiz grade averaged over ten quizzes. Nine students out of twenty-four tended to over-estimate their level of understanding as reflected in their final quiz average. Three students received failing grades on their quiz average. 


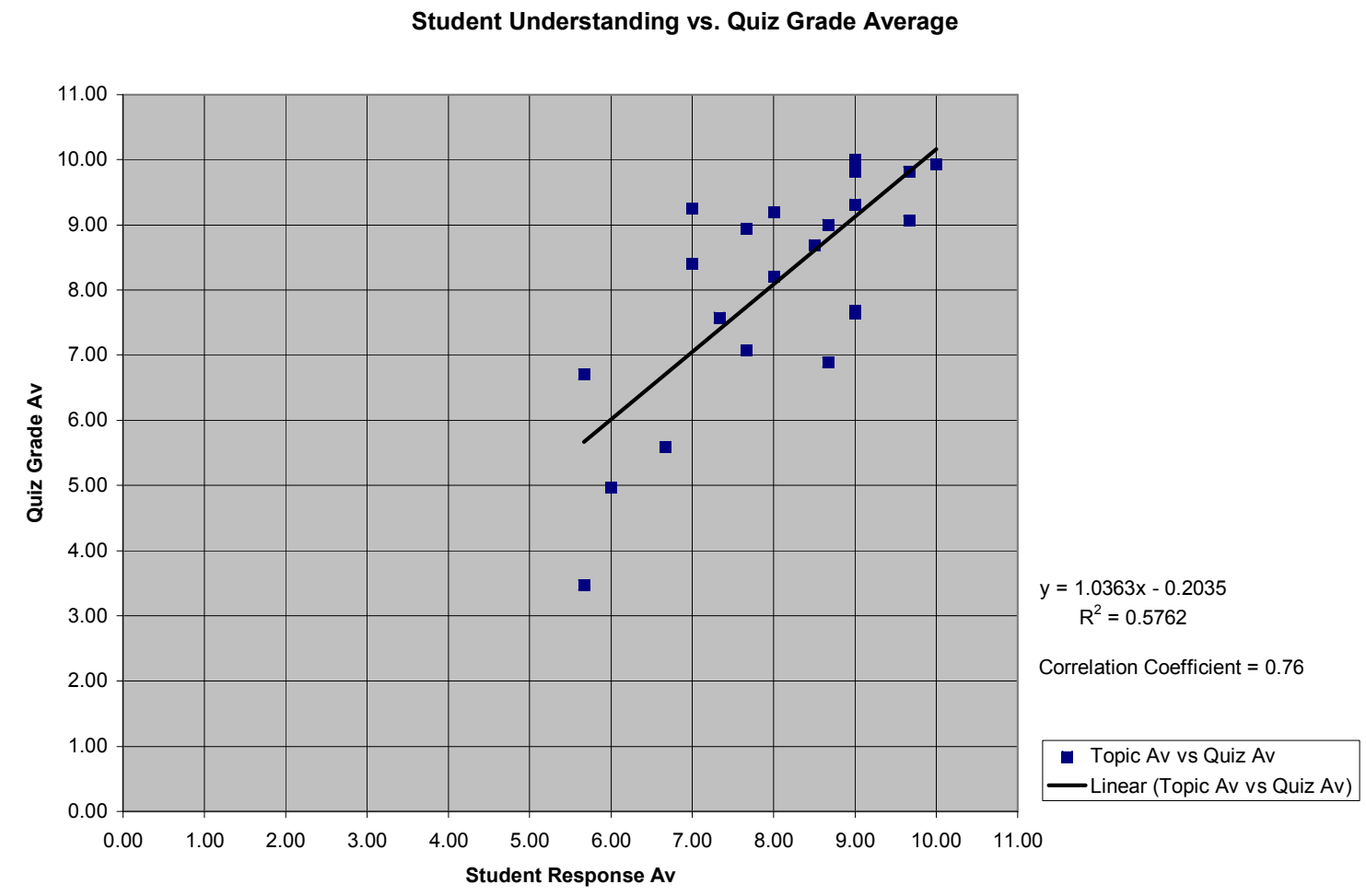

Figure 2 - Student understanding vs. overall quiz average for the course.

Figure 3 shows the relationship between student understanding (averaged over three topics) and the final exam grade. The final exam consisted of ten problems, one for each topic, and accounted for $30 \%$ of the class grade. Nine students out of twenty-four over-estimated their level of understanding as reflected in their final exam grade. Three students received failing grades on their final exam.

Figure 4 shows the relationship between student understanding (averaged over three topics) and the final course grade. Nine students out of twenty-four over-estimated their level of understanding as reflected in their final course grade. Three students received failing grades in the course.

From the data, there is a reasonably good correlation between how well students think they understand the course material and the quiz average, final exam average, and course average. Some preliminary conclusions that can be drawn from the data:

- Students know how well they are doing in a class

- The quizzes and final exam are about the same level of difficulty

- It's a good idea to get feedback from students before giving a quiz. 


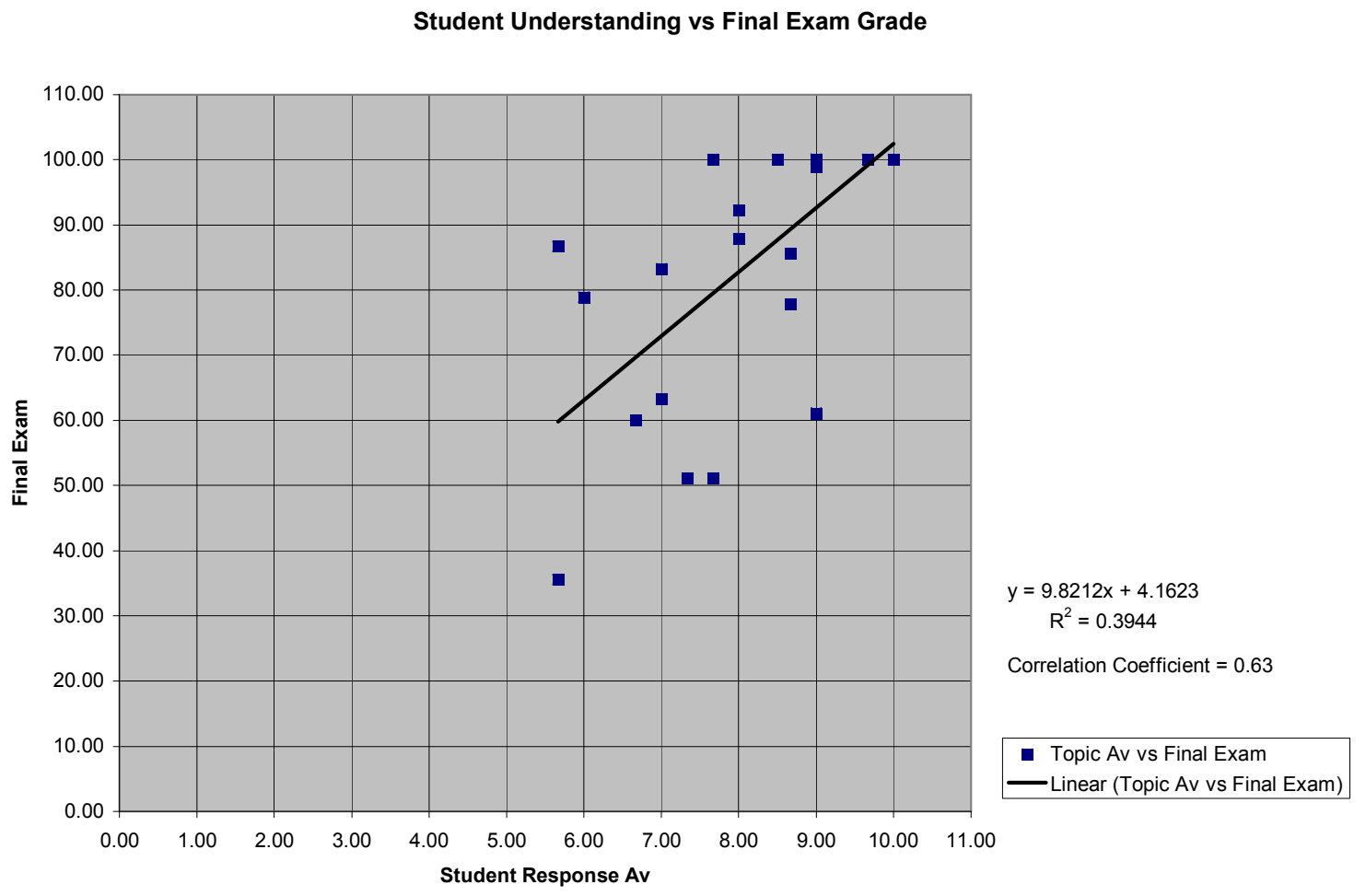

\section{Conclusion}

Figure 3 - Student understanding vs. final exam grade.

It is often difficult to get students to admit when they are having trouble with a class. In fact, the more trouble they are having, the more reluctant they are to admit it. This is probably due in part to peer pressure, but it is puzzling that some students would apparently rather fail the course or drop the course rather than admit they are having trouble. These preliminary results indicate that it may be effective to use questionnaires about student understanding as an outcomes assessment tool for individual topics in the University of South Alabama's Electrical Circuits class. The old adage "Silence is assent..." does not seem to hold here. If the instructor is proactive in asking students whether they understand the material at several critical points in the learning process, the student success rate as measured by their final grade, final exam grade, and quiz average can be improved.

It does increase the load on the instructor to process the questionnaires, but there is a benefit that is worth the extra effort. The service courses at the University of South Alabama have supplemental instructors that conduct extra problem sessions and one-on-one tutorials with students that are having trouble. The topical questionnaires give the instructor some feedback on how well the material is being assimilated prior to testing. If students are having trouble, they can be identified early and can be encouraged to take advantage of supplemental instruction before their final grade is in jeopardy. 


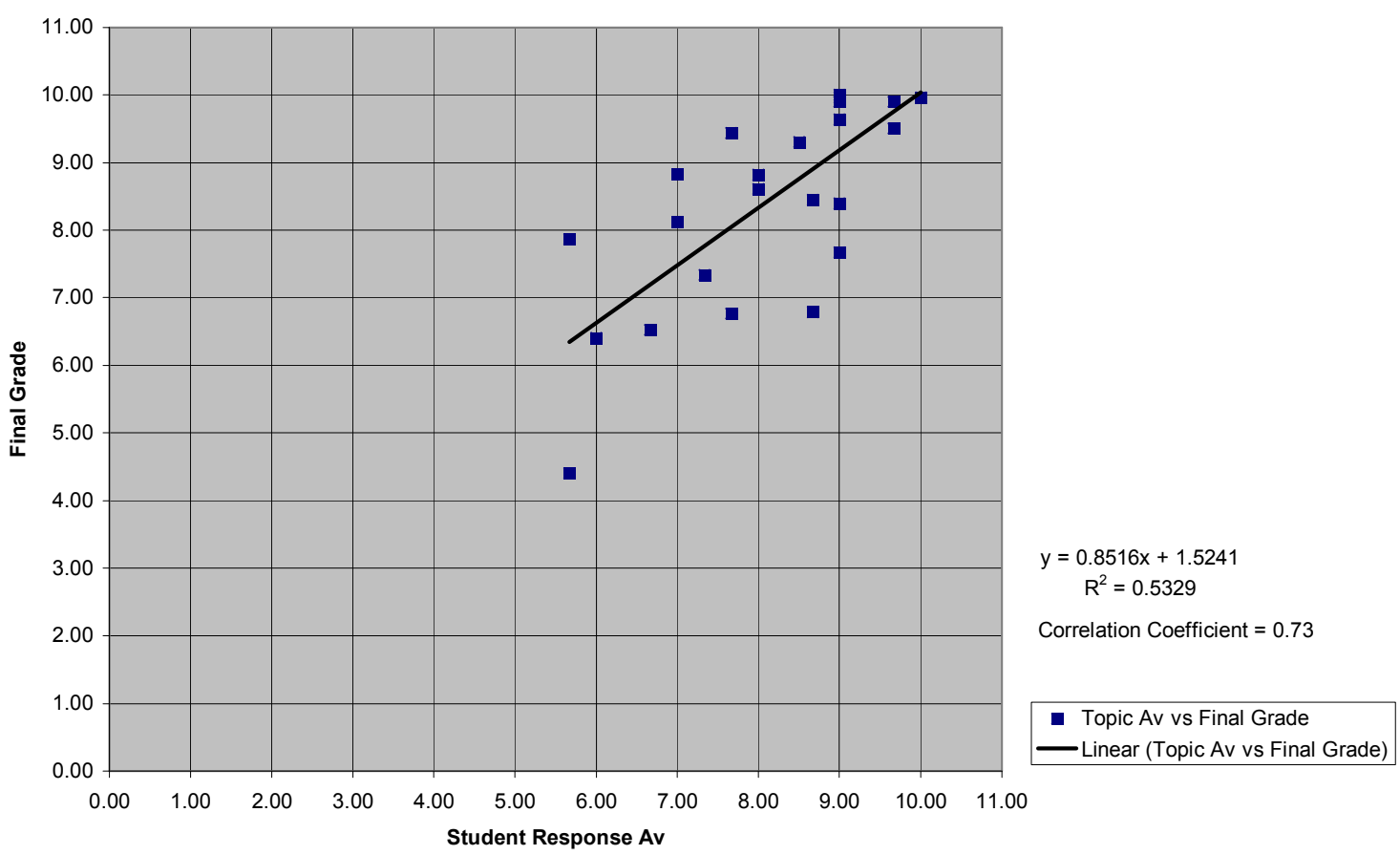

Figure 4 - Student understanding vs. final course grade.

\section{Bibliography}

1) Engineering Accreditation Commission. (2000, November). Criteria for accrediting engineering programs. Accreditation Board for Engineering and Technology, Inc. Baltimore, MD. http://www.abet.org/images/Criteria/eac_criteria_b.pdf

2) T.G. Thomas, M. Alam, "Addressing ABET 2000 requirements for continual evaluation and improvement of ECE programs," Proceedings of ASEE, vol. 3560, June 2003.

3) M.R. Parker, W.A. Stapleton, T.G. Thomas, "Post-assessment evaluation of engineering programs," presented at the Engineering Foundation Conference on Engineering Education for Global Practice in The 21st Century, Barga, Italy, April 9-14, 2000.

\section{Biographies}

DR. TOM THOMAS is an Assistant Professor of Electrical Engineering at the University of South Alabama in Mobile, Alabama. He received his Ph.D. from the University of Alabama in Huntsville in 1997. His research interests include neural network-based signal processing, environmental monitoring, and engineering education. Email address: thomas@usouthal.edu.

DR. MARTIN PARKER is a Professor of Electrical Engineering at the University of South Alabama in Mobile, Alabama. He received his Ph.D. from Salford University, United Kingdom, in 1971. He has over 
100 refereed publications and his research interest include magnetics, electromagnetism, and engineering education. Email address: mparker@usouthal.edu. 